\title{
Sensitivity Analysis of Reprocessing Cooling Times on Light Water Reactor and Sodium Fast Reactor Fuel Cycles
}

R. M. Ferrer

S. Bays

M. Pope

April 2008

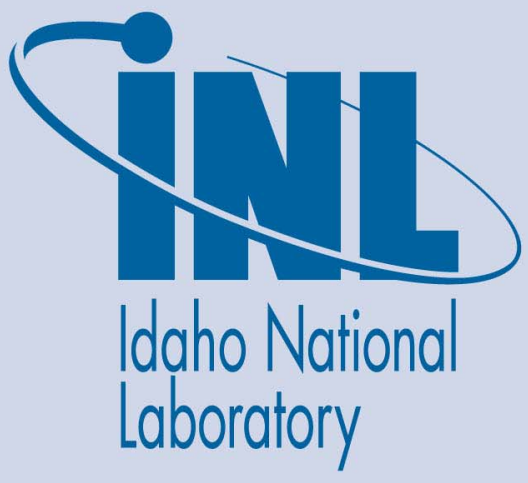

The INL is a U.S. Department of Energy National Laboratory operated by Battelle Energy Alliance 


\title{
Sensitivity Analysis of Reprocessing Cooling Times on Light Water Reactor and Sodium Fast Reactor Fuel Cycles
}

\author{
R. M. Ferrer \\ S. Bays \\ M. Pope
}

April 2008

\begin{abstract}
Idaho National Laboratory
Idaho Falls, Idaho 83415
\end{abstract}




\section{Sensitivity Analysis of Reprocessing Cooling Times on Light Water Reactor and Sodium Fast Reactor Fuel Cycles}

INL/EXT-08-14200

April 2008

Approved by

Rodolfo M. Ferrer, Principal Author

Date

Mehdi Asgari, Reactor Physics Analysis and

Date

Design Department Manager

Kathryn McCarthy, Systems Analysis Campaign

Date

Director 


\section{ABSTRACT}

The purpose of this study is to quantify the effects of variations of the Light Water Reactor (LWR) Spent Nuclear Fuel (SNF) and fast reactor reprocessing cooling time on a Sodium Fast Reactor (SFR) assuming a single-tier fuel cycle scenario. The results from this study show the effects of different cooling times on the SFR's transuranic (TRU) conversion ratio (CR) and transuranic fuel enrichment. Also, the decay heat, gamma heat and neutron emission of the SFR's fresh fuel charge were evaluated. A 1000 MWth commercial-scale SFR design was selected as the baseline in this study. Both metal and oxide $\mathrm{CR}=0.50 \mathrm{SFR}$ designs are investigated.

The baseline assumptions and perturbations on the system are based on the latest assumptions and recommendations [1]. A table summarizing these assumptions and the requested perturbations is shown below. The LWR SNF cooling time is assumed to consist nominally of a 10 year wet storage cooling period. The recommended perturbations on the wet storage time involve 1, 2, 20 and 50 year cooling periods. The SFR discharged fuel cooling time is assumed to be nominally 1 year for metal and 10 years for oxide fuels. The recommended perturbations on this parameter involve 1, 2, 20, and 50 year cooling periods for both metal and oxide fuels. The separation and fabrication time is assumed to be 1 year and is kept constant for both UOX and SFR discharged fuel.

\begin{tabular}{|c|c|c|c|}
\hline Parameter & Nominal & Sensitivity/Perturbation & $\begin{array}{c}\text { Sensitivity - parameter } \\
\text { range }\end{array}$ \\
\hline UOX time lags & $\begin{array}{l}\underline{\mathbf{1 0}} \mathrm{yr} \text { min wet cooling } \\
=11 \text { total recycle time } \\
=11 \text { sab }\end{array}$ & & $\begin{array}{l}\text { Wet cooling varies } \\
1,2, \underline{\mathbf{1 0}}, 20,50\end{array}$ \\
\hline SFR time lags & $\begin{array}{l}\text { For metal fuel } \\
\mathbf{1} \mathrm{yr} \text { 'wet' } \\
1 \mathrm{yr} \text { sep }+\mathrm{fab} \\
=2 \mathrm{yr} \text { total recycle time }\end{array}$ & $\begin{array}{l}\text { For oxide fuel } \\
\underline{\mathbf{1 0}} \mathrm{yr} \text { 'wet' } \\
1 \mathrm{yr} \text { sep }+ \text { fab } \\
=11 \text { yr total recycle time }\end{array}$ & $\begin{array}{l}\text { Interim cooling varies } \\
1,2, \underline{\mathbf{1 0}}, 20,50\end{array}$ \\
\hline
\end{tabular}

The results from these scenarios, which involve representative core performance data, corresponding to an equilibrium fuel cycle, have been submitted to the VISION team at INL for further system analysis. The purpose of these calculations performed by the INL fuel cycle group for the VISION team is to ensure that the scenarios are feasible from a reactor physics and neutronics perspective.

In general, the necessary TRU enrichment was observed to increase (relative to the TRU enrichment for the 1 year cooling period) as the LWR SNF and SFR discharge cooling times became longer for equal cycle length in both metal and oxide fuel SFR cases. Consequently, the TRU CR decreased (again, relative to the TRU CR for the 1 year cooling period) as the cooling time became longer. This effect is mainly due to the decay of Pu-241 into Am-241, which decreases the reactivity of the makeup feed as cooling time increases. Thus, a larger TRU enrichment is required and a larger amount of minor actinides is present throughout the core.

Equilibrium charge fuel data, such as decay heat, gamma heating, and neutron emission was also collected in each parameter scan. The SFR equilibrium charge decay heat was observed to slightly increase (relative to the 1 year cooling period) as the LWR SNF cooling time increased. This effect is due to the higher presence of Am-241, Cm-242 (decay product of Am-242), and Pu-238 (decay product of Cm-242) in the external fuel LWR makeup feed. However, as the SFR discharge cooling time was increased (again, relative to the 1 year cooling period), the decay heat decreases by roughly half after a 30 year-cooling period. This is due to the decay of $\mathrm{Cm}-244$, which has an 18.1 year half-life. Thus, 
perturbations on the SFR reprocessing cooling time had a greater effect on the equilibrium charge decay heat than LWR SNF cooling time. The SFR charged fuel equilibrium gamma heat was found to increase (relative to the 1 year cooling period) as the LWR SNF cooling time increased due to the Pu-241 decay into Am-241. The gamma heating increases in the SFR discharge cooling time perturbation (again, relative to the 1 year cooling period) as the cooling time increases, mainly due to the decay of $\mathrm{Pu}-241$ into Am-241. The gamma heating in this case, however, reaches a maximum roughly corresponding to the half-life of Pu-241 (14.35 years) and begins to decrease due to the decay of Cm-244. Finally, the neutron emission decreases as the cooling time for the LWR SNF and SFR discharge fuel increases (both relative to the 1 year cooling period). 


\section{DISCLAIMER}

This report was prepared as an account of work sponsored by an agency of the United States Government. Neither the United States Government nor any agency thereof, or any of their employees, makes any warranty, express or implied, or assumes any legal liability or responsibility for the accuracy, completeness, or usefulness of any information, apparatus, product, or process disclosed, or represents that its use would not infringe privately owned rights. Reference herein to any specific commercial product, process, or service by trade name, trademark, manufacturer, or otherwise, does not necessarily constitute or imply its enforcement, recommendation, or favoring by the United States Government or any agency thereof. The views and opinions of authors expressed herein do not necessarily state or reflect those of the United States Government or any agency thereof. 


\section{ACKNOWLEDGEMENTS}

The authors would like to thank Steve Piet (INL) for his contributions. 


\section{CONTENTS}

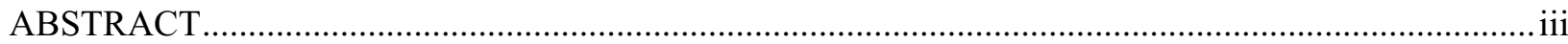

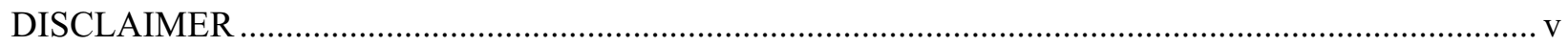

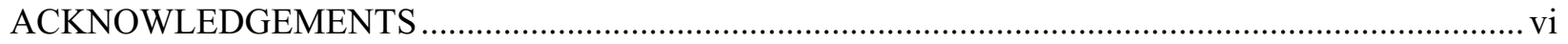

GLOSSARY, ACRONYMS, AND ABBREVIATIONS ….............................................................

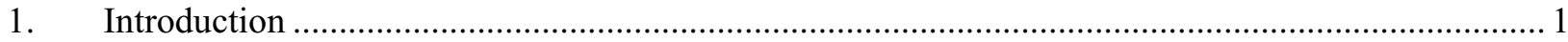

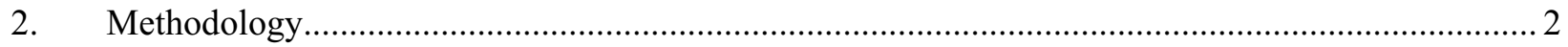

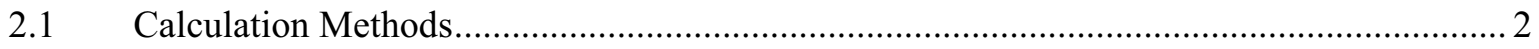

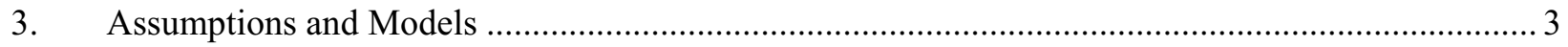

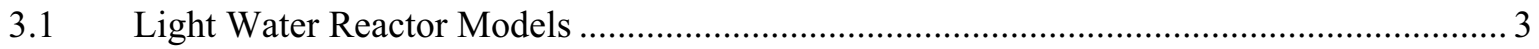

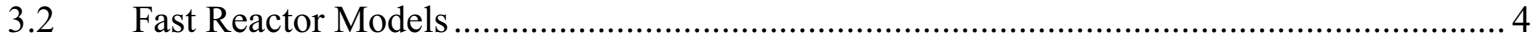

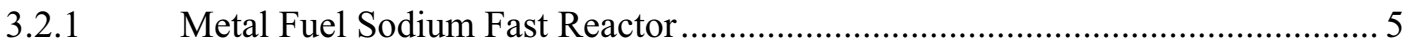

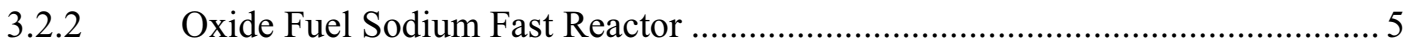

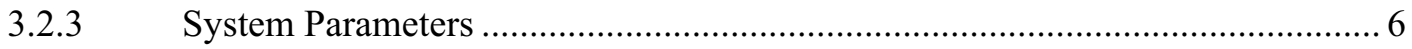

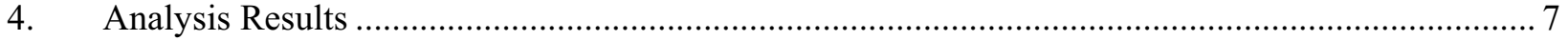

4.1 Light Water Reactor Cooling Time Results ......................................................... 7

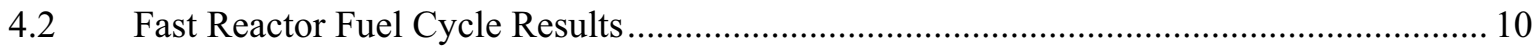

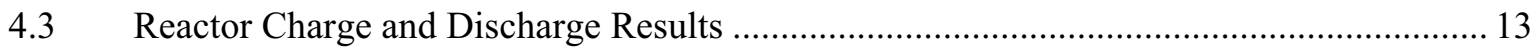

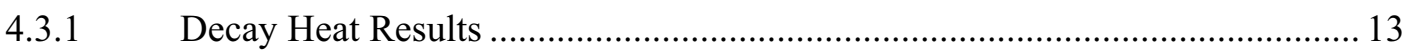

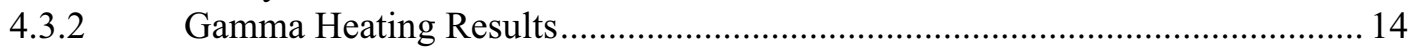

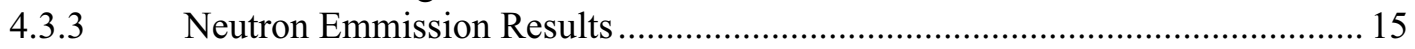

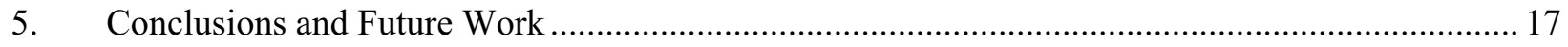

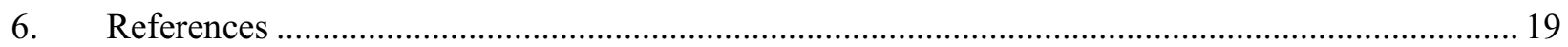




\section{FIGURES}

Figure 3-1 One Third Symmetric Radial Layout of Metal Fuel CR=0.50 SFR Design. ........................... 5

Figure 3-2 One Third Symmetric Radial Layout of Oxide Fuel CR=0.50, 0.75 SFR Design................... 6

Figure 4-1 Concentration of $\mathrm{Np}, \mathrm{Pu}, \mathrm{Am}$, and $\mathrm{Cm}$ in LWR SNF after various decay periods of wet storage

(Each color bar represents and isotopes mass).

Figure 4-2 Concentration of selected TRU in LWR SNF after various decay periods of wet storage......... 8

Figure 4-3 Log-Linear Plot of concentration of TRU in LWR SNF after various decay periods of wet storage.

Figure 4-4 TRU CR as function of LWR SNF cooling time. ............................................................. 11

Figure 4-5 TRU CR as function of SFR discharged fuel cooling time............................................... 11

Figure 4-6 TRU enrichment as function of LWR SNF cooling time................................................... 12

Figure 4-7 TRU enrichment as function of SFR discharged fuel cooling time. ..................................... 12

Figure 4-8 Decay heat as function of LWR SNF cooling time......................................................... 13

Figure 4-9 Decay heat as function of SFR discharged fuel cooling time. ........................................... 14

Figure 4-10 Gamma heat as function of LWR SNF cooling time. ..................................................... 14

Figure 4-11 Gamma heat as function of SFR discharged fuel cooling time.......................................... 15

Figure 4-12 Neutron emission as function of LWR SNF cooling time. ................................................. 15

Figure 4-13 Neutron emission as function of SFR discharged fuel cooling time................................... 16 


\section{TABLES}

Table 1-1 Summary of Nominal and Perturbations on Fuel Cycle Parameters. .......................................... 1

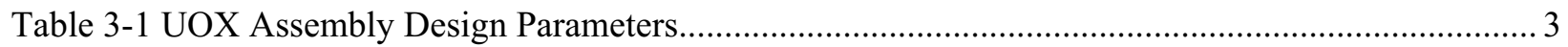

Table 3-2 Fuel Assembly Design for Metal and Oxide Fuel CR=0.50 SFR ........................................ 4

Table 3-3 Definition of System Parameters of Interest...................................................................... 6

Table 4-1 Parameters Varied for Metal SFR TRU CR=0.50 ......................................................... 9

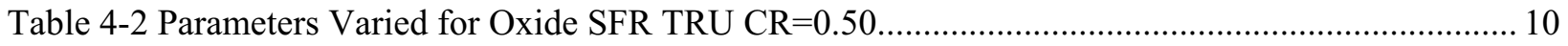

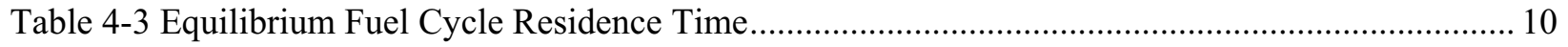

Table 5-1 Results of Perturbations on Fuel Cycle Parameters for Metal Fuel CR=0.50 SFR.................. 18

Table 5-2 Results of Perturbations on Fuel Cycle Parameters for Oxide Fuel CR=0.50 SFR.................. 18 


\title{
GLOSSARY, ACRONYMS, AND ABBREVIATIONS
}

\author{
ANL Argonne National Laboratory \\ DOE Department of Energy \\ GNEP Global Nuclear Energy Partnership \\ INL Idaho National Laboratory \\ LWR Light Water Reactor \\ MA Minor Actinides \\ $M^{2}-2 \quad$ Code System for Calculating Fast Neutron Spectra and Multigroup \\ Cross-Sections \\ MOX Mixed-Oxide Fuel \\ ORNL Oak Ridge National Laboratory \\ REBUS-3 Code System for Analysis of Fast Reactor Fuel Cycles \\ RSICC Radiation Safety Information Computational Center \\ SFR Sodium Fast Reactor \\ S-PRISM SuperPRISM Advanced Fast Reactor \\ SNF Spent Nuclear Fuel \\ TRU Transuranics \\ TRU CR Transuranic Conversion Ratio \\ UOX Uranium-Oxide Fuel \\ UREX Uranium Extraction Process \\ VISION Verifiable Fuel Cycle Simulation of Nuclear Fuel Cycle Dynamics
}




\section{Introduction}

A 1000 MWth Sodium Fast Reactor (SFR) transuranic burner-type design [2-3] was selected as the baseline in this scenario study. A transuranic conversion ratio (TRU CR) of 0.50 was assumed, along with other nominal assumptions [1]. Metal and oxide fuel SFR designs were considered. The fuel cycle analysis group at the Idaho National Laboratory (INL) analyzed and provided VISION isotope data for the requested perturbations on the LWR SNF and SFR discharge cooling time. The VISION code is a computer based simulation model that allows the performance of dynamic simulations of fuel cycles to quantify infrastructure requirements and identify key trade-offs between alternatives. Since direct neutronic calculations are not performed within the model, 'recipes' for different reactor types must be provided by the fuel cycle analysis group in the form of VISION-formatted isotope data.

A summary of the assumptions and requested perturbations is shown in Table 1-1. The LWR SNF cooling time is assumed to consist nominally of a 10 year wet storage period. The recommended perturbations on the wet storage time involve 1,2, 20 and 50 year cooling periods. The SFR discharged fuel cooling time is assumed to be nominally 1 year for metal and 10 years for oxide fuels. The recommended perturbations on this parameter involve 1,2,20, and 50 year cooling periods for both metal and oxide fuels. The separation and fabrication time is assumed to be 1 year and is kept constant in both UOX and SFR discharged fuel.

Table 1-1 Summary of Nominal and Perturbations on Fuel Cycle Parameters.

\begin{tabular}{|c|c|c|c|}
\hline Parameter & Nominal & Sensitivity/Perturbation & $\begin{array}{c}\text { Sensitivity - parameter } \\
\text { range }\end{array}$ \\
\hline UOX time lags & $\begin{array}{l}\frac{\mathbf{1 0}}{1} \mathrm{yr} \text { min wet cooling } \\
=11 \text { total recycle time }\end{array}$ & & $\begin{array}{l}\text { Wet cooling varies } \\
1,2, \underline{\mathbf{1 0}}, 20,50\end{array}$ \\
\hline SFR time lags & $\begin{array}{l}\text { For metal fuel } \\
\underline{1} \text { yr 'interim' } \\
1 \text { yr sep }+ \text { fab } \\
=2 \text { yr total recycle time }\end{array}$ & $\begin{array}{l}\text { For oxide fuel } \\
\underline{\mathbf{1 0}} \text { yr 'interim' } \\
1 \text { yr sep }+ \text { fab } \\
=11 \text { yr total recycle time }\end{array}$ & $\begin{array}{l}\text { Interim cooling varies } \\
\underline{\mathbf{1}}, 2, \underline{\mathbf{1 0}}, 20,50\end{array}$ \\
\hline
\end{tabular}

Representative core performance data at equilibrium has been submitted to the VISION team at INL for further understanding as to how these four scenarios affect the fuel cycle system as a whole. The purpose of these calculations is to ensure that the scenarios are neutronically feasible. In addition to providing 'recipes' for each scenario, TRU enrichment and CR, important fuel handling data is collected, such as equilibrium charge decay heat, gamma heating, and neutron emission. The assumptions and approaches used in this analysis are outlined and data from the results presented and discussed. 


\section{Methodology}

\subsection{Calculation Methods}

\section{Light Water Reactor Calculations}

The calculations were performed using the TRITON code that is part of the SCALE 5.1 package [4]. The TRITON code [5] acts as a link between the transport code NEWT and the depletion code ORIGEN$\mathrm{S}$ [6]. The calculations thus track all isotopes available in ORIGEN-S, which numbers in the thousands. The results for these isotopes are then processed according to the requirements of the VISION team to a subset of 81 isotopes.

\section{Fast Reactor Calculations}

The fast reactor codes $\mathrm{MC}^{2}-2$ [7] and REBUS-3 [8] were used to generate multi-group fast spectrum cross-sections and to perform fuel cycle calculations. The $\mathrm{MC}^{2}-2$ code was used to generate 33 energygroup cross section sets (group constants) for each of the fuel enrichment zones, reflectors and shields. Starting with an ultra-fine group ENDF/B-V cross section library, $\mathrm{MC}^{2}-2$ creates collapsed cross section sets by performing a critical buckling search. These cross section sets are subsequently concatenated into a single data file so that they may be used by the fuel cycle code REBUS-3 to perform an enrichment search for an equilibrated fuel cycle given user-defined constraints, such as burnup limit.

The REBUS-3 nodal diffusion option in hexagonal-z geometry was used to perform the flux calculations. In our fuel cycle model, individual fuel assemblies within a region (enrichment region) are homogenized utilizing representative neutron spectra. Therefore, independent batches of fuel are tracked within the external fuel cycle but not explicitly spatially represented in the physics calculation. Furthermore, the constraints in the equilibrium calculations involved a search of the specific fresh fuel charge enrichment given a peak fast fluence limit. An automated scripting system is used to re-calculate the cross-sections for each enrichment zone based on that zone's fuel inventory at equilibrium. This ensures that the group constants correspond to the equilibrium case (since the initial cross section set is based only on an estimate of the actual TRU enrichment). Since REBUS-3 only deals with the closed portion of the fuel cycle, the externally supplied feed is made sufficiently large to provide the reprocessing with enough heavy metal to constitute the next batch of fresh fuel.

\section{Decay Heat, Gamma Heating, and Neutron Emission}

The depletion code ORIGEN-S was used to predict the concentration of isotopes after cooling and storage. SCALE 5.1 was also used to calculate the decay heat, gamma heating, and neutron emission heat for the beginning-of-equilibrium cycle (BOEC) mass charge reported by REBUS-3 and was normalized on a per kg-TRU basis 


\section{Assumptions and Models}

This section presents brief discussion of the LWR and SFR models. Detailed thermal-hydraulics and material considerations, such as linear power limits and thermal conductivity models for the metal and oxide fuels, are discussed in detail in previous reports [2]. The methodology applied to the perturbation of the conversion ratio involved a reduction in pin diameter, which effectively reduces the fuel volume fraction. This causes the TRU enrichment to increase and consequently the conversion ratio to decrease for the same fuel cycle. Once again, detailed descriptions of this process and its effects on the thermal performance of the assembly design are available in other reports [2]. Finally, it is assumed that the LWR and SFR operate on a single tier fuel cycle in which the LWR SNF is used as makeup feed for the SFR.

\subsection{Light Water Reactor Models}

The LWR core data and parameters assumed for LWR calculations are summarized in Table 3-1. It is assumed that the commercial sector is composed of LWRs using uranium oxide (UOX) fuel. For the purpose of this study it is also assumed that data for pressured water reactors (PWRs) is a good representative of the commercial fleet; in actuality only $2 / 3$ of LWRs in the U.S. are PWRs. The data are for a PWR with 193 assemblies operating at 3000 MWth containing bundles with 264 fuel pins with an active fuel height of $3.6576 \mathrm{~m}$, one instrument channel and 24 guide tubes. The specific power of the core is assumed to be $33.69 \mathrm{~W} / \mathrm{g}$ for $51 \mathrm{GWD} / \mathrm{MTHM}$ burnup. Reactivity balance and mass flow data for the LWR UOX and MOX cores were obtained using the linear reactivity model (LRM) and unit assembly model assuming core leakage of 3.5\%; a three-batch core is assumed.

Table 3-1 UOX Assembly Design Parameters.

\begin{tabular}{|l|l|}
\hline & $\begin{array}{l}\text { Tier 0 } \\
\text { (Both Scenarios) }\end{array}$ \\
\hline Assembly size & 17 x 17 \\
\hline Number of fuel pins & 264 UOX \\
\hline Number of guide tubes (GT) & 24 \\
\hline Number of instrumentation tubes (IT) & 1 \\
\hline Fuel rod pitch $(\mathrm{cm})$ & 1.26 \\
\hline Inter-assembly gap $(\mathrm{cm})$ & 0.08 \\
\hline Fuel pellet radius $(\mathrm{cm})$ & 0.4096 \\
\hline Clad inner radius $(\mathrm{cm})$ & 0.4178 \\
\hline Clad outer radius $\left(\mathrm{cm}^{2}\right)$ & 0.4750 \\
\hline Smeared fuel density $\left(\mathrm{g} / \mathrm{cm}^{3}\right)$ & 9.88 \\
\hline Zr clad density $\left(\mathrm{g} / \mathrm{cm}^{3}\right)$ & 6.55 \\
\hline Coolant density $\left(\mathrm{g} / \mathrm{cm}^{3}\right)$ & 0.7116 \\
\hline GT/IT inner radius $\left(\mathrm{cm}^{3}\right)$ & 0.5715 \\
\hline GT/IT outer radius $\left(\mathrm{cm}^{3}\right)$ & 0.6121 \\
\hline Specific power density $(\mathrm{MW} / \mathrm{MTHM})^{1)}$ & 33.69 \\
\hline Fuel temperature $(\mathrm{K})$ & 900 \\
\hline Cladding temperature $(\mathrm{K})$ & 630 \\
\hline Bulk coolant temperature $(\mathrm{K})$ & 580 \\
\hline
\end{tabular}




\subsection{Fast Reactor Models}

The strategy followed in the reduction of the conversion ratio of the SFR models from the original S-PRISM designs was to reduce the fuel pin diameter in the fuel assemblies.

The fuel assembly cold dimensions, along with the fuel pin design and volume fractions for the reference metal and oxide SFRs, are listed in Table 3-2. The original S-PRISM assembly design had 271 pins per assembly, while the assembly designs for the metal and oxide $\mathrm{CR}=0.50 \mathrm{SFR}$ has 324 pins per assembly. The reduced thermal conductivity and/or fuel solidus temperature of higher TRU enriched fuel pins required a larger number of pins per assembly in order to reduce the average linear power to an acceptable limit. The shrinking of the fuel pin diameter also entails using spacer grids instead of wire wrap in the assembly design, thus the difference between the $\mathrm{CR}=0.50$ (higher TRU enrichment). The detailed design and geometry of the control rod mechanism, reflector, and shield can be found in other reports. It suffices to say that these are modeled as homogenous regions and are very similar to those proposed for the S-PRISM design [2].

Table 3-2 Fuel Assembly Design for Metal and Oxide Fuel CR=0.50 SFR.

\begin{tabular}{|c|c|c|}
\hline & Metal CR $=0.50$ & Oxide $\mathrm{CR}=0.50$ \\
\hline Assembly pitch, cm & 16.142 & 16.142 \\
\hline $\begin{array}{c}\text { Inter-assembly gap, } \\
\mathrm{cm}\end{array}$ & 0.432 & 0.432 \\
\hline $\begin{array}{l}\text { Duct outside flat-to- } \\
\text { flat, cm }\end{array}$ & 15.710 & 15.710 \\
\hline Duct material & HT9 & HT9 \\
\hline Duct thickness & 0.394 & 0.394 \\
\hline $\begin{array}{c}\text { Fuel Pins per } \\
\text { Assembly }\end{array}$ & 324 & 324 \\
\hline Spacer Type & Grid & Grid \\
\hline Bond & $\mathrm{Na}$ & $\mathrm{He}$ \\
\hline Core Height, cm & 101.60 & 137.16 \\
\hline Plenum Height, $\mathrm{cm}$ & 191.14 & 170.82 \\
\hline $\begin{array}{l}\text { Overall Pin Length, } \\
\mathrm{cm}\end{array}$ & 407.04 & 422.28 \\
\hline $\begin{array}{c}\text { Fuel Smeared/ } \\
\text { Fabrication Density, } \\
\% \text { TD }\end{array}$ & $75 / 100$ & $85 / 89.4$ \\
\hline Pin Diameter, cm & 0.623 & 0.658 \\
\hline $\begin{array}{l}\text { Cladding Thickness, } \\
\mathrm{cm}\end{array}$ & 0.0559 & 0.0635 \\
\hline $\begin{array}{l}\text { Wire Wrap Diameter, } \\
\mathrm{cm}\end{array}$ & N/A & N/A \\
\hline $\begin{array}{c}\text { Pin Pitch-to-diameter } \\
\text { Ratio } \\
\end{array}$ & 1.293 & 1.224 \\
\hline \multicolumn{3}{|l|}{ Vol. Fractions, \%: } \\
\hline Fuel & 22.08 & 30.22 \\
\hline Bond & 7.36 & 1.56 \\
\hline Structure & 26.41 & 29.22 \\
\hline Coolant & 44.15 & 39.00 \\
\hline
\end{tabular}




\subsubsection{Metal Fuel Sodium Fast Reactor}

The radial layout of the metal $\mathrm{CR}=0.50 \mathrm{SFR}$ core consists of three driver fuel regions; the inner, middle, and outer core. A schematic of this layout is shown below in Figure 3-1. The inner core consists of four rows containing a total of 42 assemblies. The middle core consists of two rows containing a total of 66 assemblies with a charge TRU enrichment of 1.25 times that of the inner core. The outer core consists of a single row containing 36 assemblies with a charge TRU enrichment of 1.50 times that of the inner core. Such an enrichment splitting allows for the flattening of the power distribution. The reflector and shield regions of the core correspond to the last three rows of the core. While the ultimate shutdown and primary control rods are shown in the schematic, these were modeled as fully withdrawn.

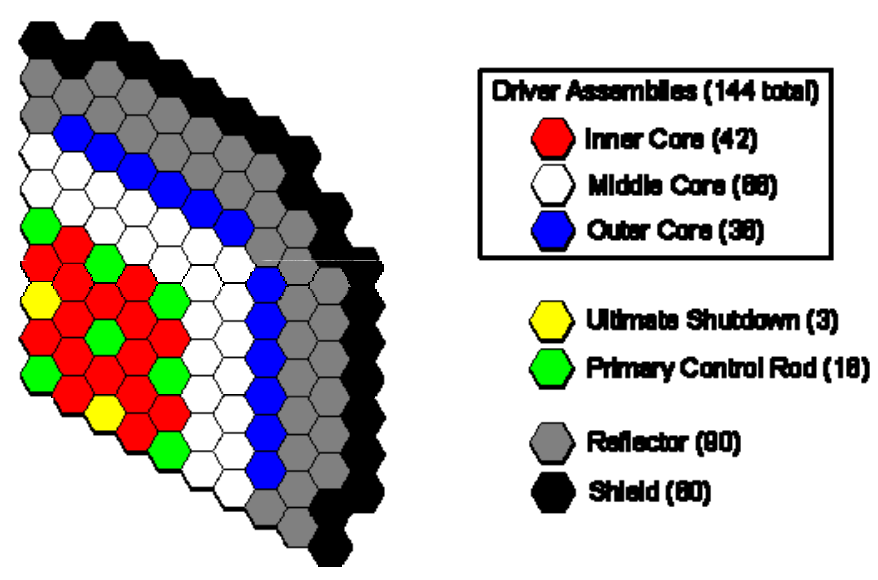

Figure 3-1 One Third Symmetric Radial Layout of Metal Fuel CR=0.50 SFR Design.

\subsubsection{Oxide Fuel Sodium Fast Reactor}

The radial layout of the oxide core, similar to the metal SFR, consists of three driver fuel regions; the inner, middle, and outer core. A schematic of this layout is shown below in Figure 3-2. The inner core consists of five rows containing a total of 72 assemblies while the middle core consists of one row containing a total of 36 assemblies with a charge TRU enrichment of 1.25 times that of the inner core. Finally, the outer core consists of a single row containing 36 assemblies with a charge TRU enrichment of 1.50 times that of the inner core. The reflector, shield, the ultimate shutdown and primary control rods were modeled as fully withdrawn. 

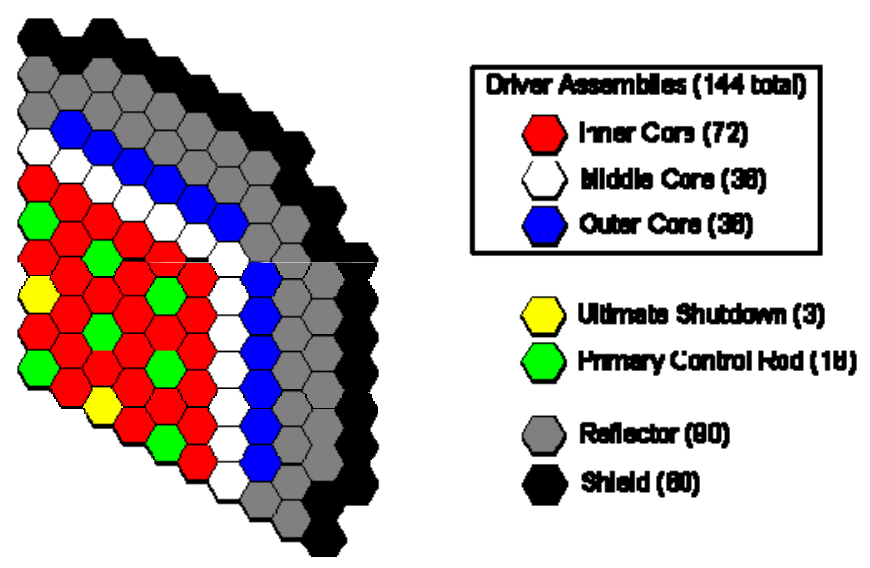

Figure 3-2 One Third Symmetric Radial Layout of Oxide Fuel CR=0.50, 0.75 SFR Design.

\subsubsection{System Parameters}

This study involved varying the nominal parameters for the 'wet' cooling time presented in the second and third columns of Table 1-1 according to the specified ranges presented in the fourth column. The effects of the various cooling times were observed on five parameters: TRU CR, TRU enrichment, charge specific decay heat, specific gamma heating, and specific neutron emission. Since the enrichment search and fuel cycle calculations are performed in 'equilibrium mode', these parameters are reported for a core in which, for a fixed cycle length, the necessary TRU enrichment has reached a steady-state value from cycle to cycle. Each parameter is defined in Table 3-3 below.

Table 3-3 Definition of System Parameters of Interest

\begin{tabular}{|c|c|}
\hline System Parameter & Definition \\
\hline TRU CR & $\begin{array}{c}\text { The rate of transuranic isotope } \\
\text { mass produced divided by the } \\
\text { rate of transuranics consumed in } \\
\text { the core from BOL to EOL }\end{array}$ \\
\hline TRU Enrichment & $\begin{array}{c}\text { Volume percent of transuranic } \\
\text { isotopes present in the SFR fuel } \\
\text { at BOL }\end{array}$ \\
\hline Specific Charge Decay Heat & $\begin{array}{c}\text { Energy released from isotopic } \\
\text { decay at BOEC from reprocessed } \\
\text { fuel divided by the mass in kg of } \\
\text { initial HM }\end{array}$ \\
\hline Specific Charge Gamma Heat & $\begin{array}{c}\text { Energy released from isotopes } \\
\text { that decay through gamma } \\
\text { emission at BOEC from }\end{array}$ \\
& $\begin{array}{c}\text { reprocessed fuel divided by the } \\
\text { mass in kg of initial HM }\end{array}$ \\
\hline $\begin{array}{c}\text { Specific Charge Neutron } \\
\text { Emission [n/s-kg-TRU] }\end{array}$ & $\begin{array}{c}\text { Total number of neutrons } \\
\text { released per second at BOEC } \\
\text { from reprocessed fuel divided by } \\
\text { the mass in kg of initial HM }\end{array}$ \\
\hline
\end{tabular}




\section{Analysis Results}

This section summarizes the results from the analysis. First, the perturbation on the LWR SNF cooling time is presented and the changes in the isotopic concentrations are discussed. In the second section the effects on the TRU CR, TRU enrichment, decay heat, gamma heating, and neutron emission are discussed.

\subsection{Light Water Reactor Cooling Time Results}

The LWR SNF transuranic discharge decay was calculated using ORIGEN-S for the various cooling periods. The concentration of neptunium, plutonium, americium and curium for each period (before being further decayed for a single year to account for separation and fabrication) is shown below in Figure 4-1.

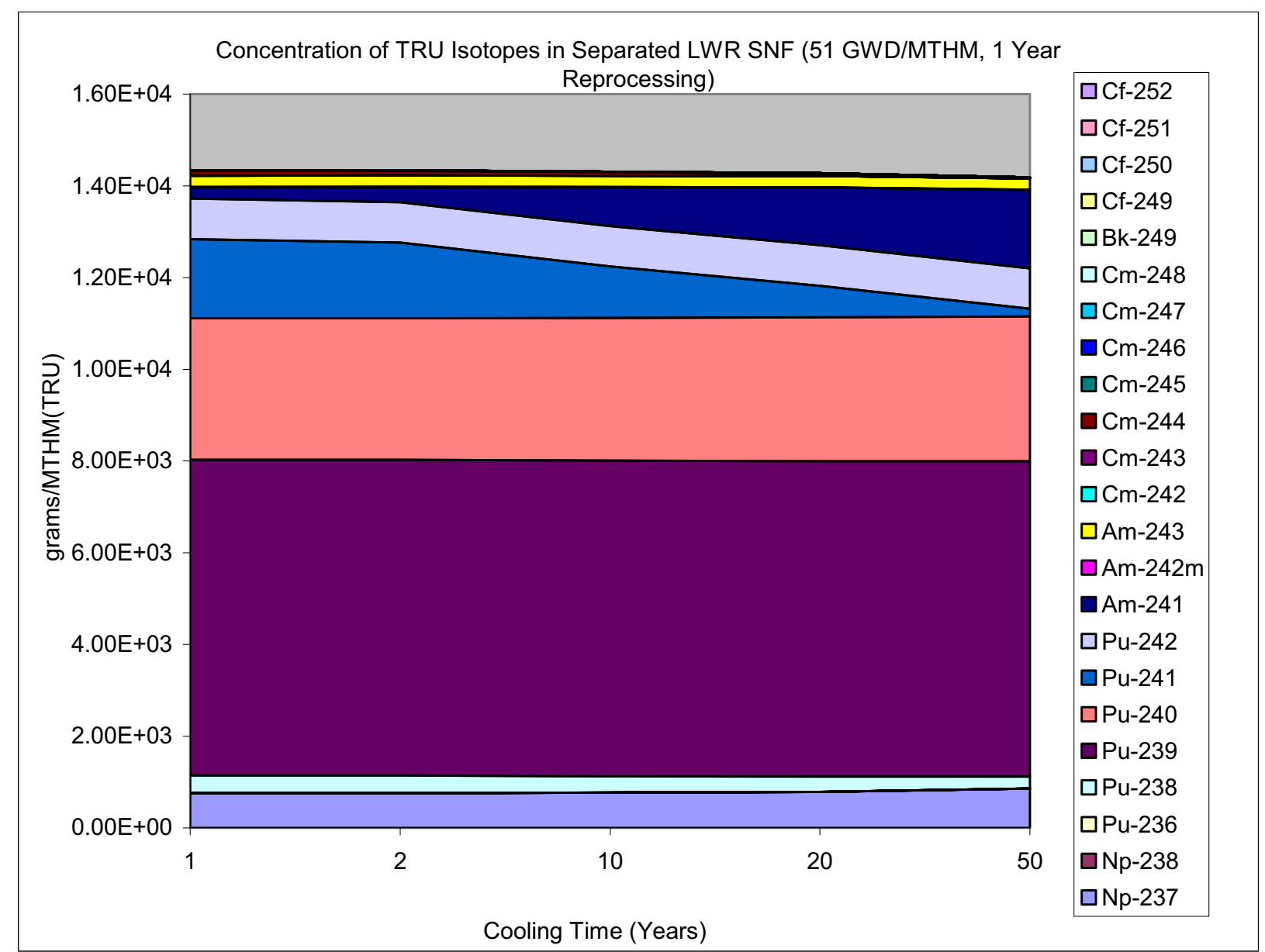

Figure 4-1 Concentration of $\mathrm{Np}, \mathrm{Pu}, \mathrm{Am}$, and $\mathrm{Cm}$ in LWR SNF after various decay periods of wet storage (Each color bar represents and isotopes mass).

It is evident from the figure above, and from decay data, that certain isotopes will be relatively stable during this decay period. On the other hand, certain isotopes will decay throughout these cooling periods. Relative to concentration (grams/MTHM-TRU), the largest change is due to the decay of Pu-241 (14.35 year half-life) into Am-241, which is shown below in Figure 4-2 


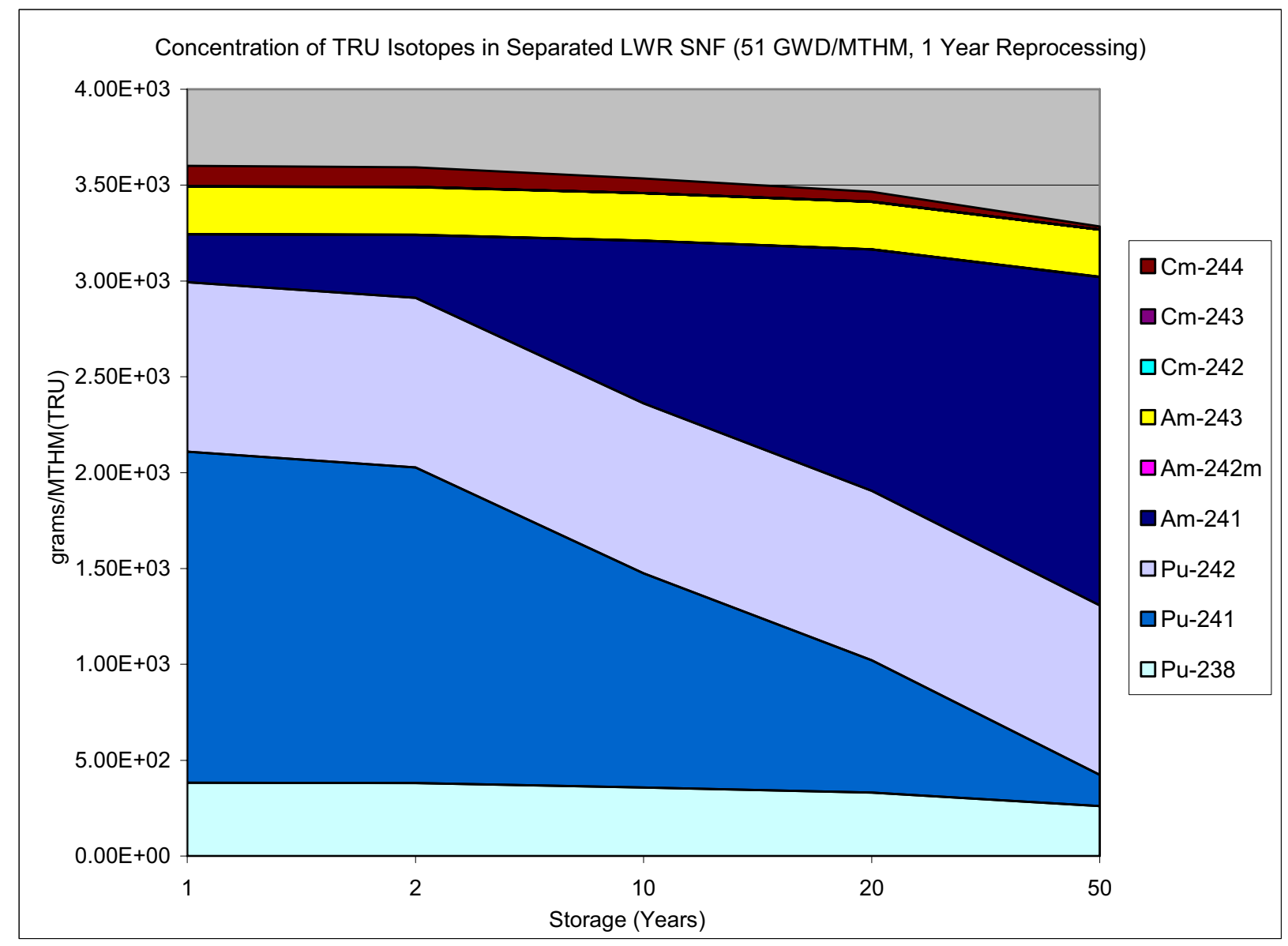

Figure 4-2 Concentration of selected TRU in LWR SNF after various decay periods of wet storage.

In order to further evaluate the decay behavior of the isotopes in the LWR SNF, it is possible to plot their concentration on a logarithmic scale. Such a plot is shown below in Figure 4-3. It reveals that while the high mass minor actinides have a relatively small concentration, Cf-252 and Cf-250 decay by several orders of magnitude over the fifty year period. 


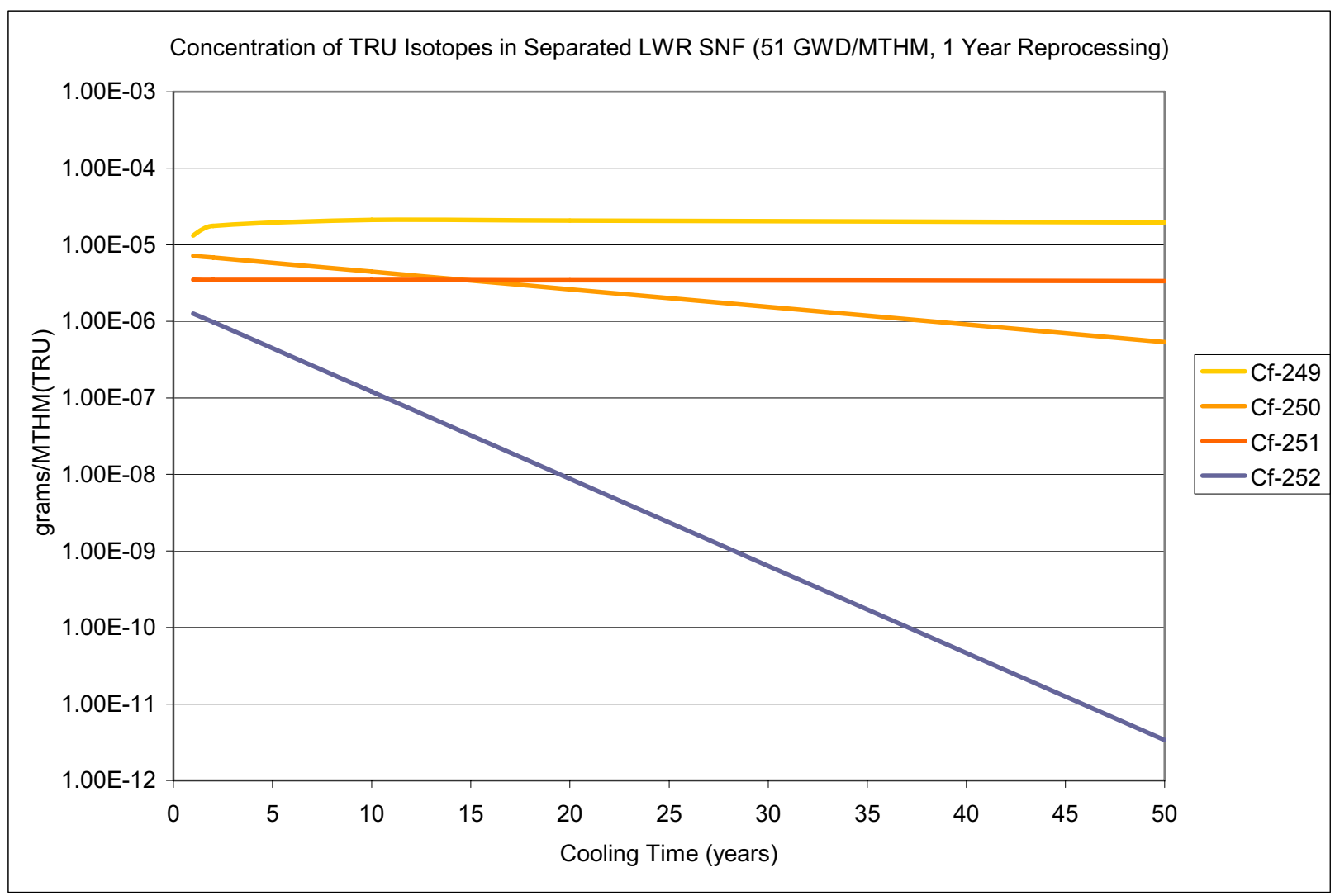

Figure 4-3 Log-Linear Plot of concentration of TRU in LWR SNF after various decay periods of wet storage.

The perturbations on the LWR SNF TRU makeup feed cooling time amount to one set of the sensitivity analysis. The second set involves the perturbation of the cooling time of the discharged fast reactor fuel before it is reprocessed into fresh fuel. Thus, a total of ten cases per fuel type were analyzed in this work. Two tables are shown below for fuel type, each of which summarizes the perturbations on the parameters of interest. The 'nominal' or 'baseline' cases are highlighted in yellow.

Table 4-1 Parameters Varied for Metal SFR TRU CR $=0.50$

\begin{tabular}{cccc}
$\begin{array}{c}\text { LWR SNF Wet } \\
\text { Storage Cooling } \\
\text { Time (Years) }\end{array}$ & $\begin{array}{c}\text { LWR SNF } \\
\text { Separation and } \\
\text { Reprocessing Time } \\
\text { (Years) }\end{array}$ & $\begin{array}{c}\text { SFR SNF } \\
\text { Cooling Time } \\
\text { (Years) }\end{array}$ & $\begin{array}{c}\text { SFR SNF } \\
\text { Reprocessing } \\
\text { Time (Years) }\end{array}$ \\
\hline 1 & 1 & 1 & 1 \\
2 & 1 & 1 & 1 \\
10 & 1 & 1 & 1 \\
20 & 1 & 1 & 1 \\
50 & 1 & 1 & 1 \\
10 & 1 & 1 & 1 \\
10 & 1 & 2 & 1 \\
10 & 1 & 10 & 1 \\
10 & 1 & 20 & 1 \\
10 & 1 & 50 & 1 \\
\hline
\end{tabular}


Table 4-2 Parameters Varied for Oxide SFR TRU CR=0.50

\begin{tabular}{cccc}
$\begin{array}{c}\text { LWR SNF Wet } \\
\text { Storage Cooling } \\
\text { Time (Years) }\end{array}$ & $\begin{array}{c}\text { LWR SNF } \\
\text { Separation and } \\
\text { Reprocessing Time } \\
\text { (Years) }\end{array}$ & $\begin{array}{c}\text { SFR SNF } \\
\text { Cooling Time } \\
\text { (Years) }\end{array}$ & $\begin{array}{c}\text { SFR SNF } \\
\text { Reprocessing } \\
\text { Time (Years) }\end{array}$ \\
\hline 1 & 1 & 10 & 1 \\
2 & 1 & 10 & 1 \\
10 & 1 & 10 & 1 \\
20 & 1 & 10 & 1 \\
50 & 1 & 10 & 1 \\
10 & 1 & 1 & 1 \\
10 & 1 & 2 & 1 \\
10 & 1 & 10 & 1 \\
10 & 1 & 20 & 1 \\
\hline 10 & 1 & 50 & 1 \\
\hline
\end{tabular}

\subsection{Fast Reactor Fuel Cycle Results}

The fast reactor fuel cycle calculation consisted in an enrichment search in which the cycle was adjusted in order to remain under the assumed peak fast fluence limit of $4.0 \times 10^{23} \mathrm{n} / \mathrm{cm}^{2}$. In order to perform a fair comparison, all cases with the same fuel type were subject to the same cycle length. Thus, it was first necessary to determine an 'initial' cycle length for all five cases (corresponding to five perturbations in cooling time), and then perform the fuel cycle calculation for all five cases with the shortest cycle length as a constraint. The cycle length, average number of batches, and resulting average residence time for the metal and oxide fuel cases is shown below in Table 4-3.

Table 4-3 Equilibrium Fuel Cycle Residence Time

$\begin{array}{cccc}\begin{array}{c}\text { Fast Reactor } \\ \text { Type }\end{array} & \begin{array}{c}\text { Cycle Length } \\ \text { (days) }\end{array} & \begin{array}{c}\text { Average } \\ \text { Number of } \\ \text { Batches }\end{array} & \begin{array}{c}\text { Average } \\ \text { Residence Time } \\ \text { (days) }\end{array} \\ \text { Metal CR=0.50 } & 209 & 6.25 & 1306.25 \\ \text { Oxide CR=0.50 } & 321 & 6.25 & 2006.25\end{array}$

The TRU CR is plotted for both metal and oxide fuel cores as a function of LWR SNF cooling time in Figure 4-4. This parameter is observed to decrease as the LWR cooling time increases. The decrease in the TRU CR is due to the net increase of the necessary TRU enrichment (relative to shorter LWR SNF cooling periods) in order to make up for reactivity lost through the decay of fissile Pu-241 into non-fissile Am-241. Thus, for feeds with equal reactivity and fixed cycle lengths, a makeup feed that has been cooled for longer will have more minor actinides per fissile plutonium than another which has not been cooled for as long. In fact, when the TRU enrichment is examined later in this section, it will be evident that it increases as the LWR SNF cooling time increases. The TRU CR curve for the oxide fuel core is observed to be lower than for the metal fuel core. This is due to baseline cooling time for discharged oxide fast reactor fuel is an order of magnitude larger than that required for the metal fuel (10 years versus 1 year), thus more time is allowed for minor actinides to build in from decay in the longer cooling time than in the shorter one. 
The results from the SFR discharge cooling time is also related to the buildup of minor actinides in the makeup feed as the cooling time increases. Figure 4-5 shows the TRU CR decreasing as the time lag between discharge and charge of the SFR fuel is increased. For an equal reprocessing cooling time of 10 years, the metal TRU CR is roughly 0.50 and the oxide TRU CR is 0.49 . This difference corresponds to slight difference in the initial $M^{2}-2 /$ REBUS3 models. Since a greater fraction of the fresh fuel TRU comes from the reprocessed feed than from the LWR SNF makeup feed, the TRU CR is more sensitive to perturbations on the SFR discharge cooling time.

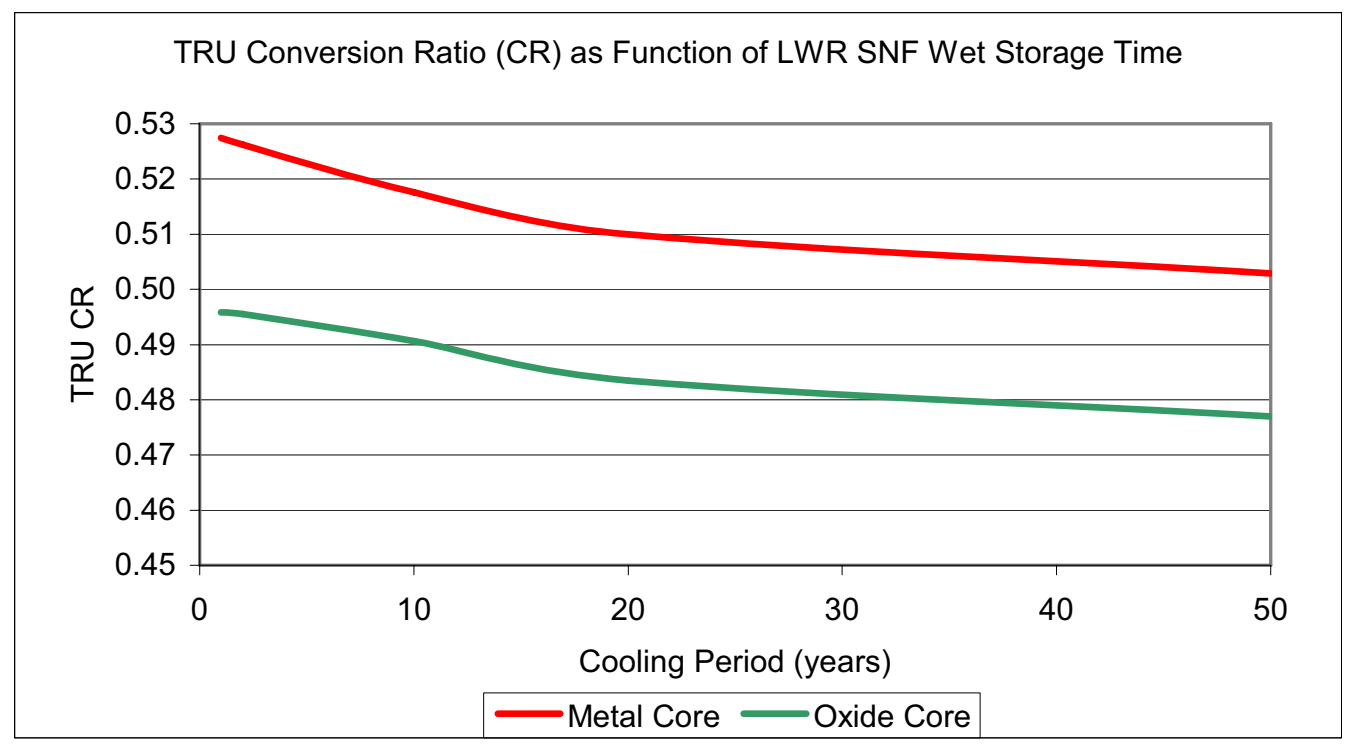

Figure 4-4 TRU CR as function of LWR SNF cooling time.

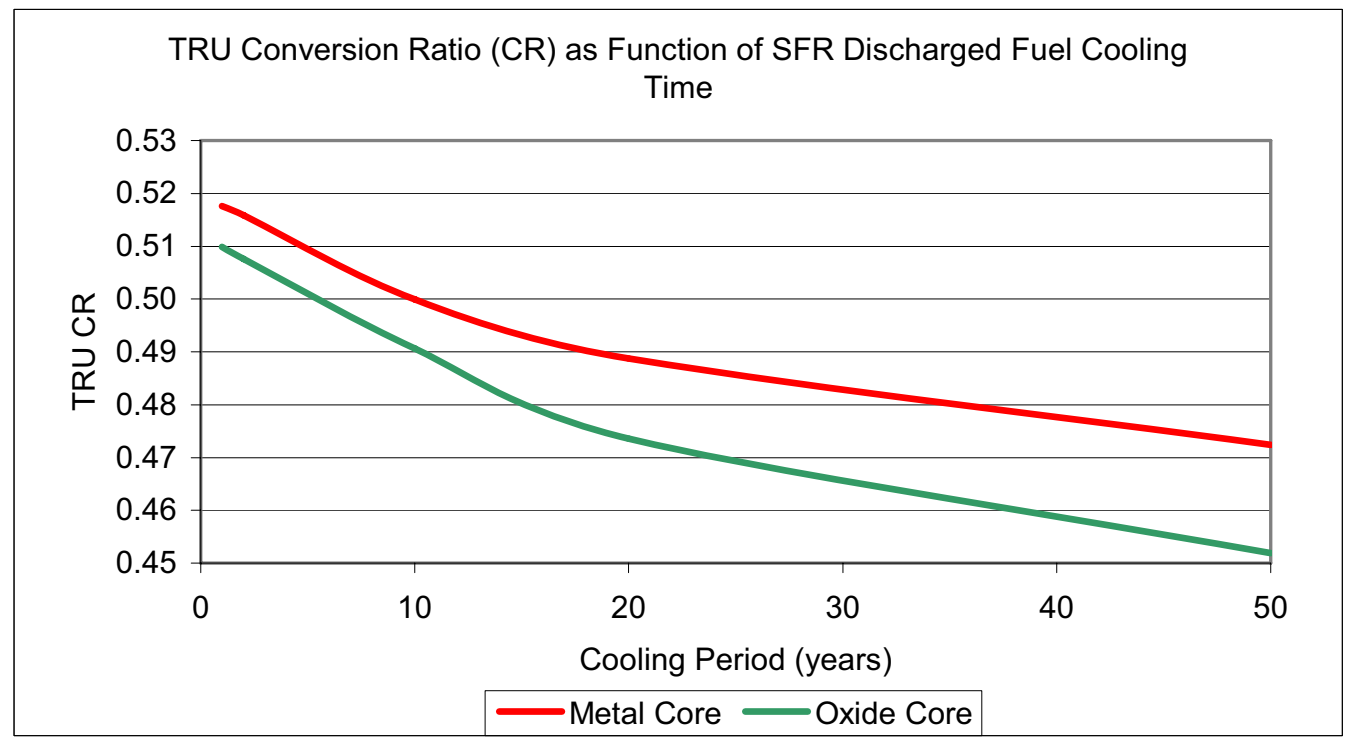

Figure 4-5 TRU CR as function of SFR discharged fuel cooling time.

In Figure 4-6 and Figure 4-7 the TRU enrichment plotted as a function of LWR and SFR cooling time. The expected trend discussed above is confirmed by the increase in the necessary TRU enrichment as the both cooling times increase. This is due to the larger presence of minor actinides in the feed 
compared to the feeds with shorter cooling times. Thus, in order to meet equal cycle lengths, the feeds with a larger fraction of minor actinides require a higher TRU enrichment.

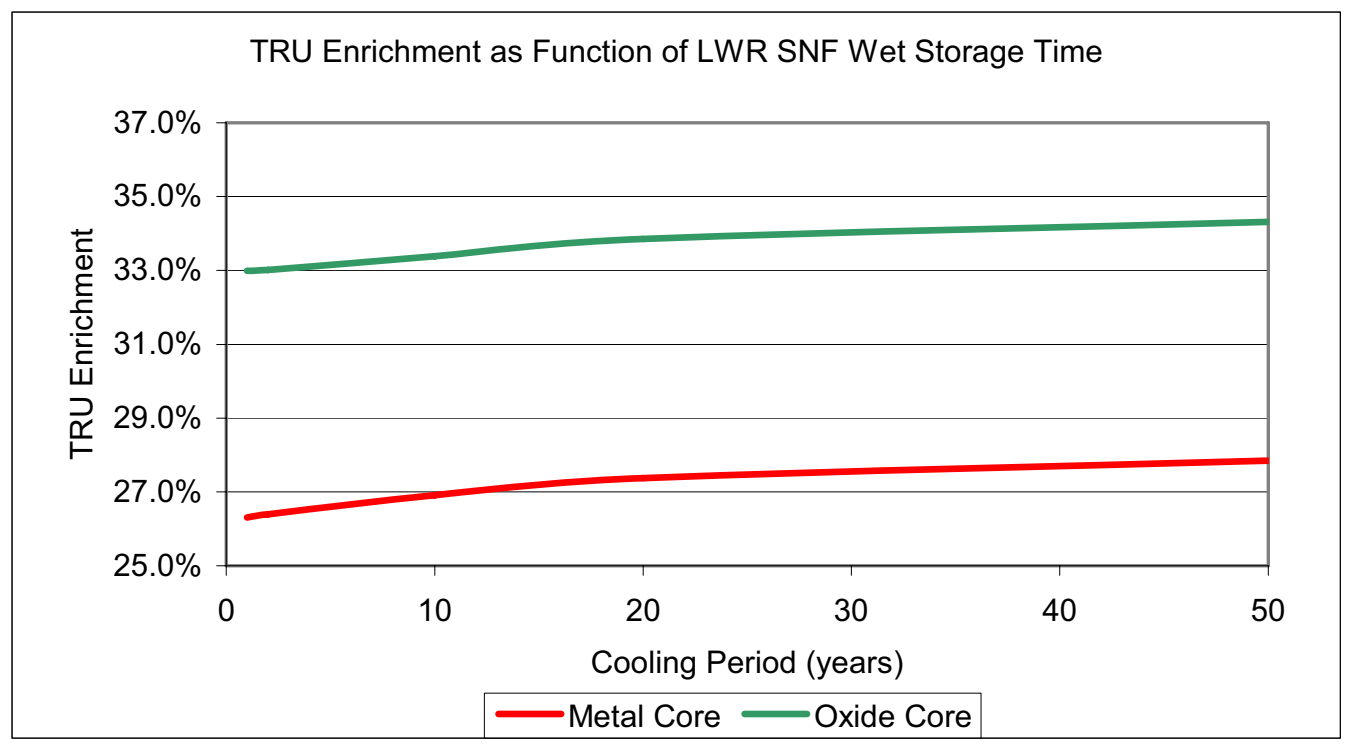

Figure 4-6 TRU enrichment as function of LWR SNF cooling time.

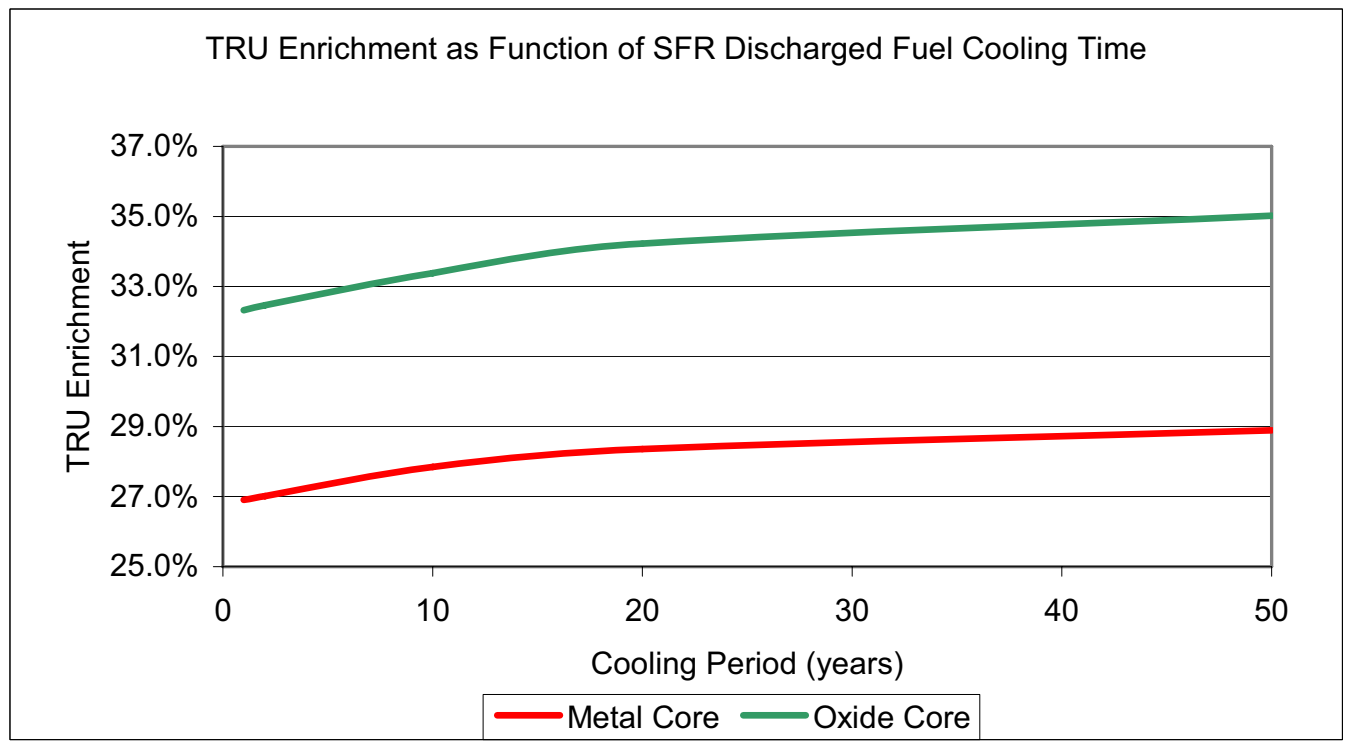

Figure 4-7 TRU enrichment as function of SFR discharged fuel cooling time. 


\subsection{Reactor Charge and Discharge Results}

The equilibrium charge mass data for all the fuel cycle scenarios were processed with internal tools and decayed using ORIGEN-S in order to calculate the decay heat, gamma heating, and neutron emission. The resulting charge neutron emission, gamma energy, and decay heat are plotted as a function of LWR SNF and SFR discharge cooling time and discussed in this section. Note that the equilibrium fresh charge fast reactor fuel combines both LWR and SFR SNF feeds.

\subsubsection{Decay Heat Results}

The 'specific' decay heat (energy per unit mass of TRU) of the fresh charged fuel is plotted as a function of LWR SNF cooling time in Figure 4-8. The decay heat for the fresh BOC fuel slightly increases as the LWR SNF cooling time increases. This is due to the higher presence of Am-241, which through neutron capture is transmuted into Am-242/Am-242 $2^{\mathrm{m}}$, which further decays into $\mathrm{Cm}-242$. This curium isotope contributes to the decay heat through alpha emission, having a short half-life (163 days). The longer-cooled LWR SNF also contains less reactivity, due to the decay accumulation of Am-241 from $\mathrm{Pu}-241$. Thus, a higher fraction of the makeup feed is drawn, which will have a higher decay heat relative to another that has a shorter cooling time. The fresh charge metal fuel has a higher decay heat than the oxide due the difference in reprocess cooling time (10 years versus 1 year).

The decay heat as a function of SFR reprocessing cooling time is shown in Figure 4-9. The longer cooling time allows Cm-244 (18.1 year half-life) to decay over time. Thus, the decay heat decreases in both metal and oxide fuel. The difference in decay heat between metal and oxide is due to the difference in TRU enrichment.

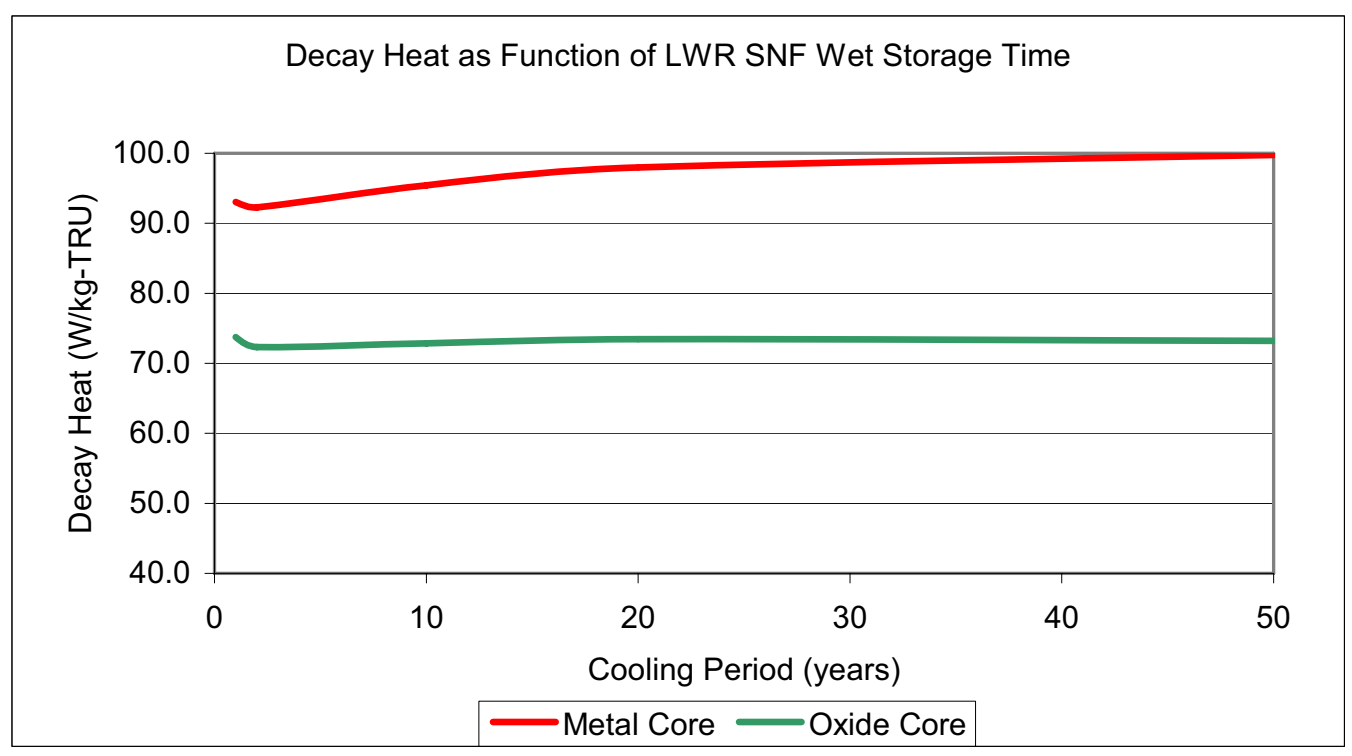

Figure 4-8 Decay heat as function of LWR SNF cooling time. 


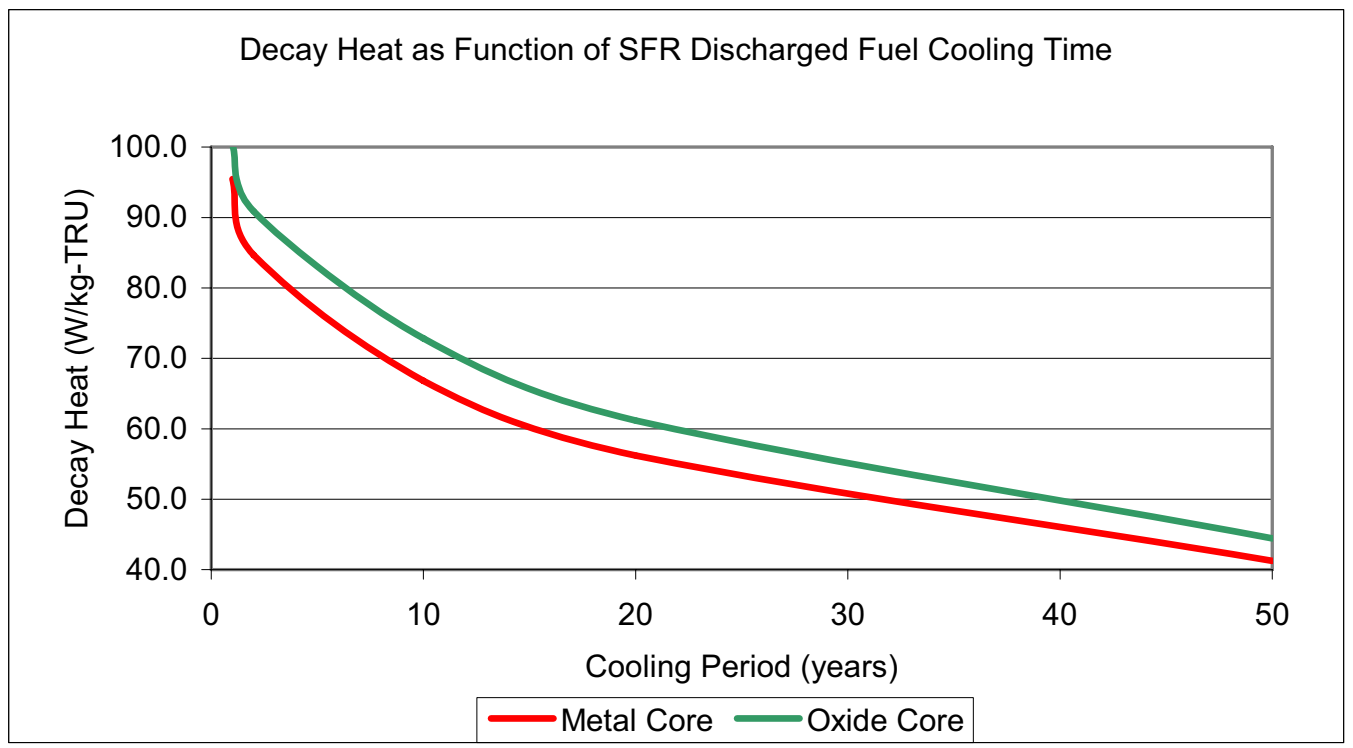

Figure 4-9 Decay heat as function of SFR discharged fuel cooling time.

\subsubsection{Gamma Heating Results}

Following the results from the decay heat calculations, the gamma heating is plotted as a function of LWR SNF cooling time in Figure 4-10 for both types of fuel. As more minor actinides buildup in the LWR SNF feed, due to the decay of fissile Pu-241 into Am-241, a higher enrichment is needed to maintain equal cycle lengths. This causes the gamma heating of the charge fast reactor fuel to increase with increasing cooling time. The gamma heating as a function of fast reactor fuel reprocessing time, plotted in Figure 4-11, shows an initial increase followed by a decrease after roughly a 20 year lag time. The decay of Pu-241 into Am-241 causes the initial increase in gamma heating. The eventual decay of Cm-244 (18.1 year half-life) causes the decrease in overall gamma heating seen in the plot.

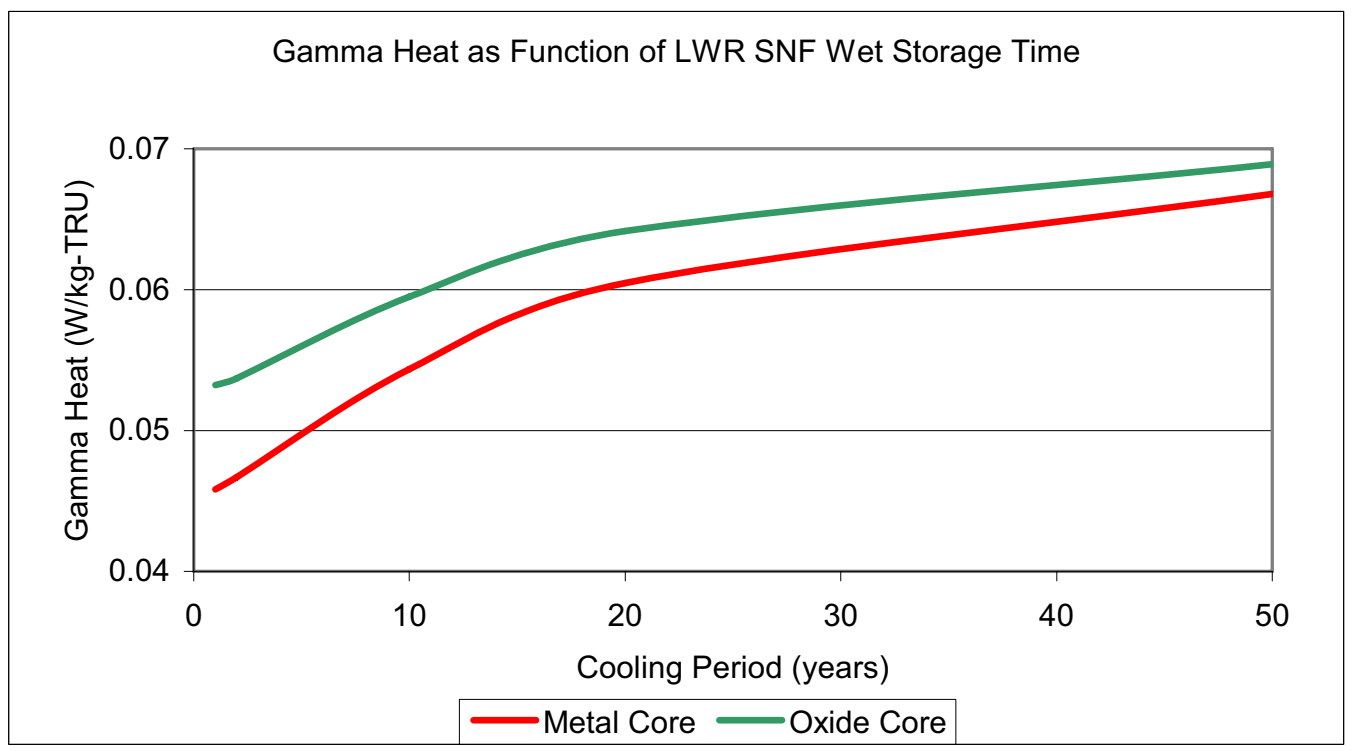

Figure 4-10 Gamma heat as function of LWR SNF cooling time. 


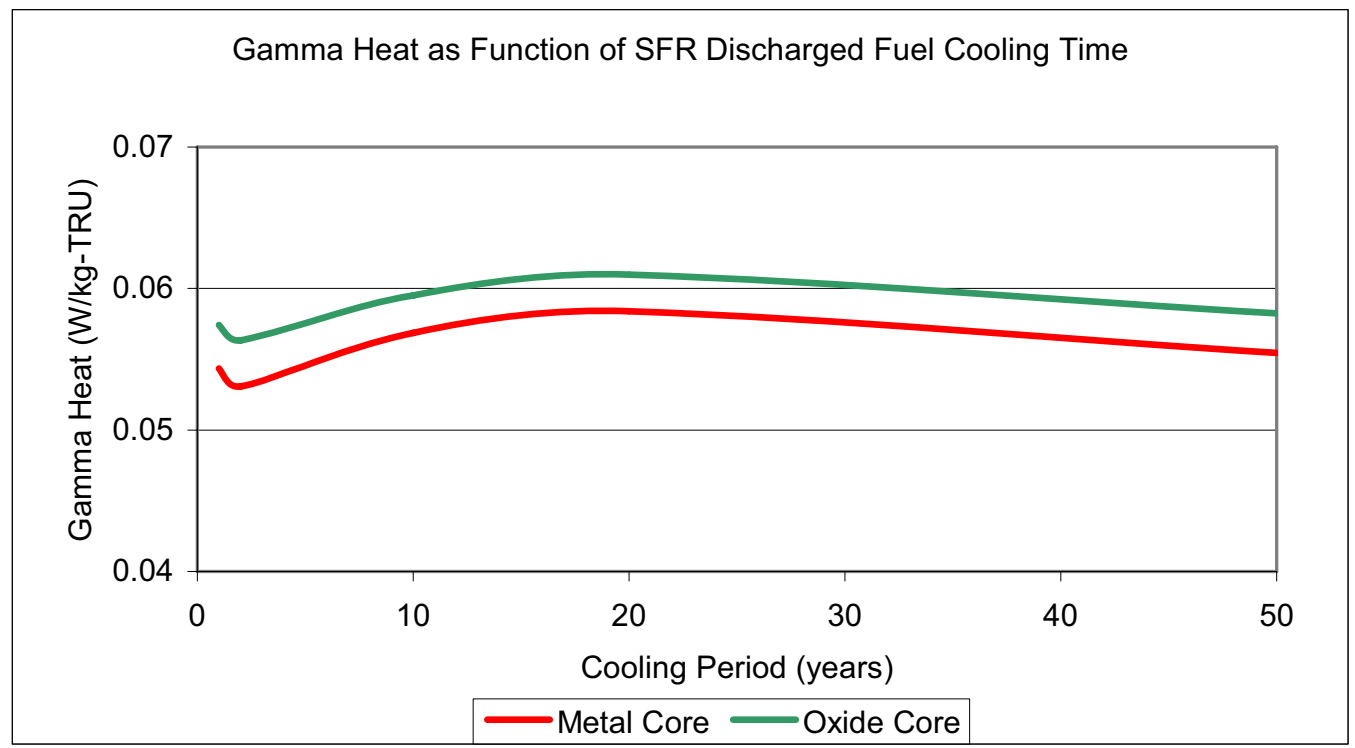

Figure 4-11 Gamma heat as function of SFR discharged fuel cooling time.

\subsubsection{Neutron Emmission Results}

The neutron emission from the fresh charge fast reactor fuel is mostly dominated by the "higher mass' minor actinides such as curium, berkelium and californium. Generally speaking, longer cooling periods allow for these isotopes to spontaneously fission, thus reduce the neutron emission. Figure 4-12 illustrates the effect of varying the LWR SNF. Since LWR discharged fuel does not contain a high concentration of these isotopes to begin with, only a slight decrease in emission is found as this feed is allowed to cool for longer periods. The metal fuel neutron emission is slightly higher than the oxide due to the shorter reprocessing cooling time of the fast reactor fuel. On the other hand, a longer period of cooling time before reprocessing fast reactor fuel can decrease the neutron emission by an order of magnitude due to decay of $\mathrm{Cm}-244$, as illustrated in Figure 4-13.

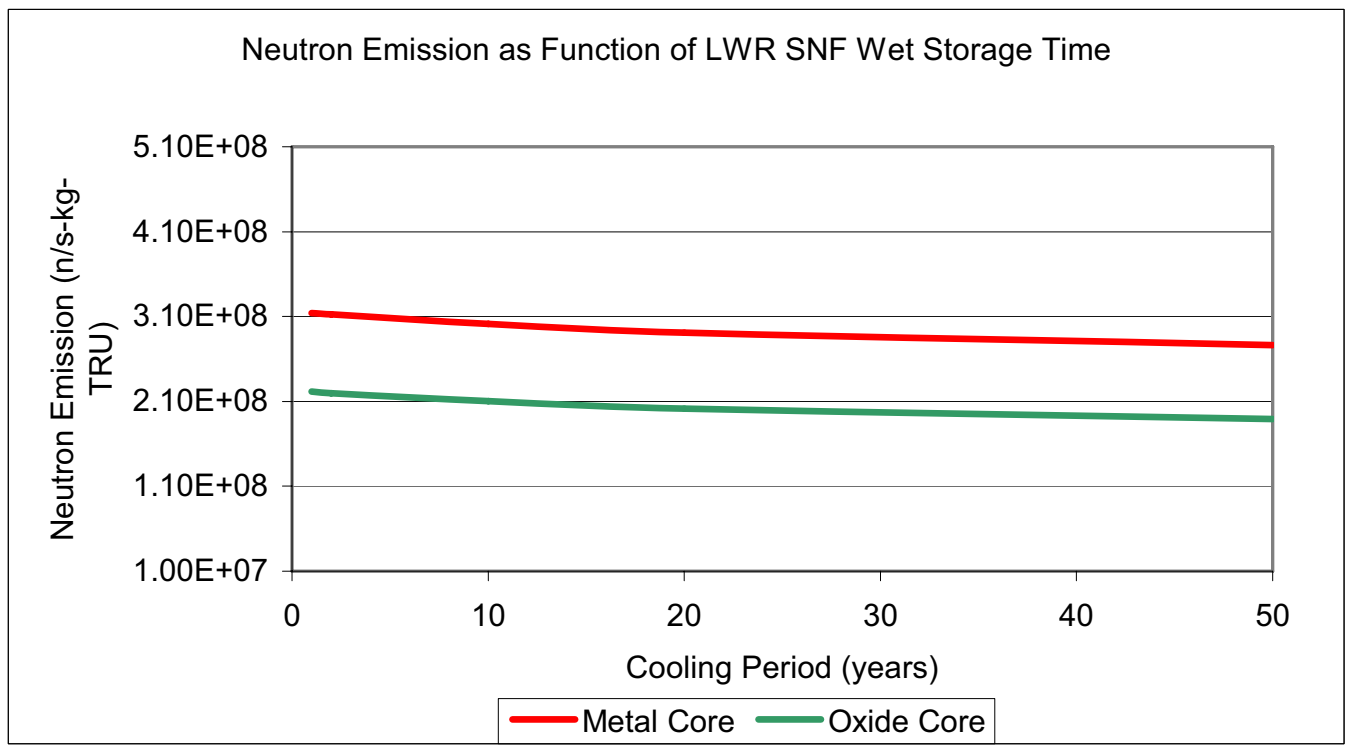

Figure 4-12 Neutron emission as function of LWR SNF cooling time. 


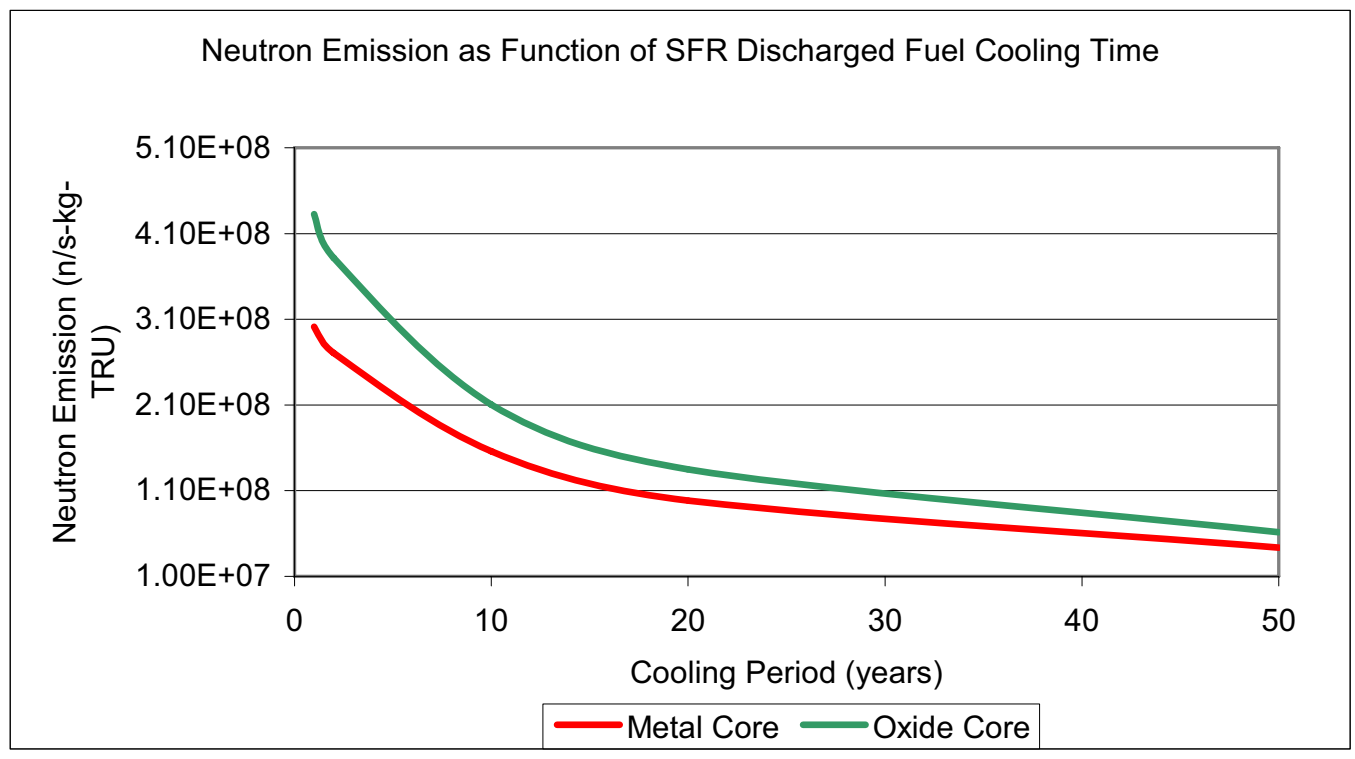

Figure 4-13 Neutron emission as function of SFR discharged fuel cooling time. 


\section{Conclusions and Future Work}

This initial study shows some of the effects that variations or perturbations on the LWR SNF and SFR discharge cooling times can have on some system parameters of interest. A transuranic conversion ratio (TRU CR) of 0.50 was assumed, along with other nominal assumptions from the DSARR report [1]. Metal and oxide fuel SFR designs were considered. The fuel cycle analysis group at the Idaho National Laboratory (INL) analyzed and provided VISION isotope data for the requested perturbations on the LWR SNF and SFR discharge cooling time.

A summary of the assumptions and requested perturbations is shown in the Introduction section (Table 1-1). The LWR SNF cooling time is assumed to consist nominally of a 10 year wet storage period. The recommended perturbations on the wet storage time involve 1, 2, 20 and 50 year cooling periods. The SFR discharged fuel cooling time is assumed to be nominally 1 year for metal and 10 years for oxide fuels. The recommended perturbations on this parameter involve 1,2, 20, and 50 year cooling periods for both metal and oxide fuels. The separation and fabrication time is assumed to be 1 year and is kept constant in both UOX and SFR discharged fuel.

Overall results, in terms of percent difference, are shown below in Table 5-1 for metal and Table 5-2 for oxide fuel. Detail discussion of the data is presented in the results section. The percent differences are calculated based on the set of cases with the shortest cooling time. The baseline or reference cases are highlighted in yellow.

In the case of the metal fuel TRU CR=0.50 SFR, extending the wet storage cooling time of the makeup feed (assuming a single tier UOX to SFR scenario), generally increases the necessary equilibrium TRU enrichment. This results in a higher overall presence of minor actinides (relative to the 1 year cooling period) in the core on the basis of equal cycle lengths. Decay heat and gamma heating were found to increase (again, relative to the 1 year cooling period) due to the decay of $\mathrm{Pu}-241$ into Am-241 and the decay of Cm-242 into Pu-238. The buildup of Cm-242 after each SFR recycle is due to the transmutation of Am-241 into Am-242, which decays into Cm-242 in secular equilibrium. A higher concentration of minor actinides in the fresh fuel causes an increase in decay heat and gamma heating due to a higher transmutation of Am-241. Neutron emission is observed to decrease as cooling time is increased.

Similar results were found with respect to the metal fuel TRU CR $=0.50$ SFR discharge cooling time perturbation. Longer cooling periods cause the TRU CR to decrease and TRU enrichment to increase (relative to the 1 year cooling period). The decay heat decreases as the SFR discharge cooling time increases (again, relative to the 1 year cooling period). This is due to the decay of Pu-238, Cm-242 and Cm-244, both of which are created after each recycle from transmuted Am-241, which originate from the LWR SNF makeup feed. The gamma heating initially increases due to the decay of Pu-241 into Am-241 and afterwards begins to decrease due to the decay of $\mathrm{Cm}-244$. It is significant to note that much of the gamma production is coupled with alpha production. This is because, even though the primary mode of decay of much of the TRU is by alpha-emission, its secondary mode is by gamma decay. Finally, the neutron emission decreases (relative to the 1 year cooling period) as the cooling time is increased. This decrease in neutron emission is mainly due to the decay of the higher mass actinides, curium, berkelium and californium, over increasingly loner cooling periods.

Results for the oxide fuel TRU CR $=0.50$ design follow the same trends as in the metal fuel case in both perturbations. 
Table 5-1 Results of Perturbations on Fuel Cycle Parameters for Metal Fuel CR=0.50 SFR.

\begin{tabular}{|c|c|c|c|c|c|c|c|c|}
\hline 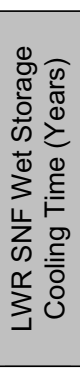 & 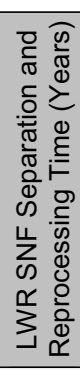 & 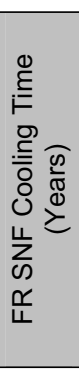 & 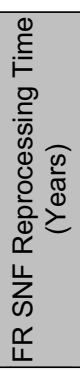 & 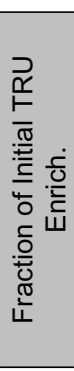 & 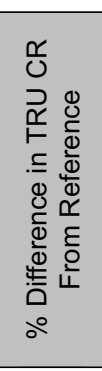 & 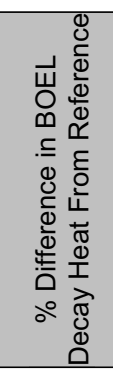 & 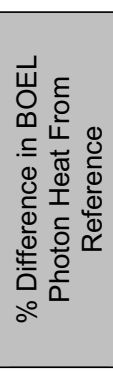 & 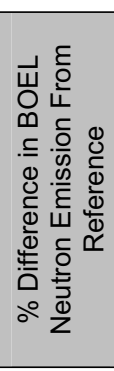 \\
\hline 1 & 1 & 1 & 1 & 1.00 & $0.00 \%$ & $0.00 \%$ & $0.00 \%$ & $0.00 \%$ \\
\hline 2 & 1 & 1 & 1 & 1.00 & $-0.24 \%$ & $-0.85 \%$ & $1.85 \%$ & $-0.61 \%$ \\
\hline 10 & 1 & 1 & 1 & 0.98 & $-1.86 \%$ & $2.55 \%$ & $18.60 \%$ & $-4.17 \%$ \\
\hline 20 & 1 & 1 & 1 & 0.96 & $-3.32 \%$ & $5.32 \%$ & $31.96 \%$ & $-7.35 \%$ \\
\hline 50 & 1 & 1 & 1 & 0.94 & $-4.66 \%$ & $7.22 \%$ & $45.76 \%$ & $-12.08 \%$ \\
\hline 10 & 1 & 1 & 1 & 1.00 & $0.00 \%$ & $0.00 \%$ & $0.00 \%$ & $0.00 \%$ \\
\hline 10 & 1 & 2 & 1 & 1.00 & $-0.33 \%$ & $-11.28 \%$ & $-2.31 \%$ & $-10.09 \%$ \\
\hline 10 & 1 & 10 & 1 & 0.97 & $-3.42 \%$ & $-30.01 \%$ & $4.63 \%$ & $-48.18 \%$ \\
\hline 10 & 1 & 20 & 1 & 0.95 & $-5.58 \%$ & $-41.09 \%$ & $7.44 \%$ & $-67.22 \%$ \\
\hline 10 & 1 & 50 & 1 & 0.93 & $-8.74 \%$ & $-56.77 \%$ & $2.03 \%$ & $-85.56 \%$ \\
\hline
\end{tabular}

Table 5-2 Results of Perturbations on Fuel Cycle Parameters for Oxide Fuel CR=0.50 SFR.

\begin{tabular}{|c|c|c|c|c|c|c|c|c|}
\hline 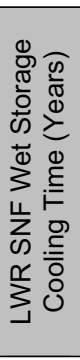 & 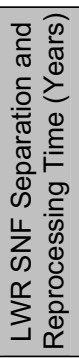 & 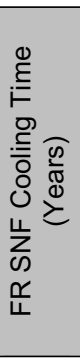 & 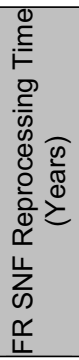 & 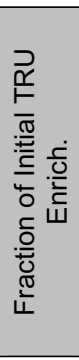 & 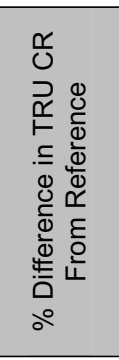 & 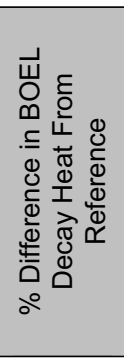 & 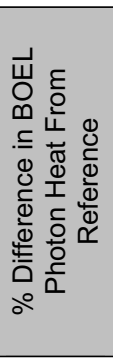 & 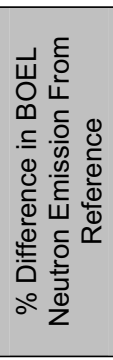 \\
\hline 1 & 1 & 10 & 1 & 1.00 & $0.00 \%$ & $0.00 \%$ & $0.00 \%$ & $0.00 \%$ \\
\hline 2 & 1 & 10 & 1 & 1.00 & $-0.06 \%$ & $-1.97 \%$ & $0.89 \%$ & $-0.89 \%$ \\
\hline 10 & 1 & 10 & 1 & 0.99 & $-1.06 \%$ & $-1.28 \%$ & $11.81 \%$ & $-5.20 \%$ \\
\hline 20 & 1 & 10 & 1 & 0.97 & $-2.50 \%$ & $-0.46 \%$ & $20.62 \%$ & $-9.03 \%$ \\
\hline 50 & 1 & 10 & 1 & 0.96 & $-3.81 \%$ & $-0.78 \%$ & $29.51 \%$ & $-14.54 \%$ \\
\hline 10 & 1 & 1 & 1 & 1.00 & $0.00 \%$ & $0.00 \%$ & $0.00 \%$ & $0.00 \%$ \\
\hline 10 & 1 & 2 & 1 & 1.00 & $-0.46 \%$ & $-9.39 \%$ & $-1.86 \%$ & $-11.72 \%$ \\
\hline 10 & 1 & 10 & 1 & 0.97 & $-3.78 \%$ & $-27.40 \%$ & $3.63 \%$ & $-51.39 \%$ \\
\hline 10 & 1 & 20 & 1 & 0.94 & $-7.12 \%$ & $-39.01 \%$ & $6.22 \%$ & $-68.82 \%$ \\
\hline 10 & 1 & 50 & 1 & 0.92 & $-11.37 \%$ & $-55.72 \%$ & $1.44 \%$ & $-85.81 \%$ \\
\hline
\end{tabular}




\section{References}

1. “Assumptions for Decision Package/DSARR Cases with the VISION Model," Idaho National Laboratory (2008).

2. R. M. FERRER, M. ASGARI, S. BAYS, and B. FORGET, "Fast Reactor Alternative Studies: Effects of Transuranic Groupings on Metal and Oxide Sodium Fast Reactor Designs," Idaho National Laboratory, INL-EXT-07-13236 (2007).

3. E. A. HOFFMAN, W. S. YANG, and R. N. HILL, "Preliminary Core Design Studies for the Advanced Burner Reactor over a Wide Range of Conversion Ratios," Argonne National Laboratory, ANL-AFCI-177 (2006).

4. SCALE: A Modular Code System for Performing Standardized Computer Analyses for Licensing Evaluation, ORNL/TM-2005/39, Version 5.1, Vols. I-III, November 2006. Available from Radiation Safety Information Computational Center at Oak Ridge National Laboratory as C00732 .

5. TRITON: A Two-Dimensional Transport and Depletion Module for Characterization of Spent Nuclear Fuel, ORNL/TM-2005/39, Revision 5.1, Vol. I, Book 3, Sect. T1, November 2006. Available from Radiation Safety Information Computational Center at Oak Ridge National Laboratory as C00-732.

6. ORIGEN-S: Scale System Module to Calculate Fuel Depletion, Actinide Transmutation, Fission Product Buildup and Decay, and Associated Radiation Source Terms, ORNL/TM-2005/39, Revision 5.1, Vol. II, Book 1, Sect. F7, November 2006. Available from Radiation Safety Information Computational Center at Oak Ridge National Laboratory as C00-732.

7. H. HENRYSON II, B. J. TOPPEL, and C. G. STENBERG, "MC'-2: A Code to Calculate Fast Neutron Spectra and Multi-Group Cross-Sections." ANL-8144, Argonne National Laboratory (1976).

8. B. J. Toppel, "A User's Guide to the REBUS-3 Fuel Cycle Analysis Capability," ANL-83-2, Argonne National Laboratory (1983). 